\section{How to get into medical school}

\author{
Vanessa Rich
}

$\mathrm{I}_{\mathrm{n}}^{\mathrm{n}}$ $n$ the fall of 2004, 555 individuals applied to Dalhousie Medical School in Halifax, Nova Scotia. Two-hundred ninety-three were invited for an interview, and when the process was complete, 90 were accepted. The remaining 465 were left to try their luck at other schools, or to wait for the following year.

This story is similar across the country. With a myriad of applicants vying for a limited number of seats in Canada's 17 medical schools, the application process is fiercely competitive.

So what led to the successful admission of current Dalhousie medical students? "The words I always use are 'balanced' and 'well-rounded," says Sharon Graham, Director of Admissions and Student Affairs at Dalhousie Medical School. While "well-rounded" is a difficult concept to define, having a breadth of knowledge and experience is clearly advantageous when attempting to gain entry into a field as vital and complex as medicine.

The role of a physician is to heal, a task for which effective communication skills are essential. Physicians are faced every day with the complex realities of life and death, handling and caring for people in their most vulnerable state. Their challenge is to balance the inherent intimacy of each encounter with the necessary objectivity, counselling and caring for their patients without assuming the burden of their conditions.

A well-rounded physician has the potential advantage of finding common ground with his or her patients, facilitating open dialogue and the establishment of trust. "Medicine is an art," says Dr. Ronald Stewart, head of the Medical Humanities Department at Dalhousie. "It involves the human condition, which is unpredictable, which involves a spiritual side. I think it's generally accepted that humanities are the base upon which you build the modern physician. If you don't have a sense of ethics, if you don't have a concept of communication, you can't go much farther."

In addition, a well-rounded physician may find it easier to deal with stressors which are an inherent part

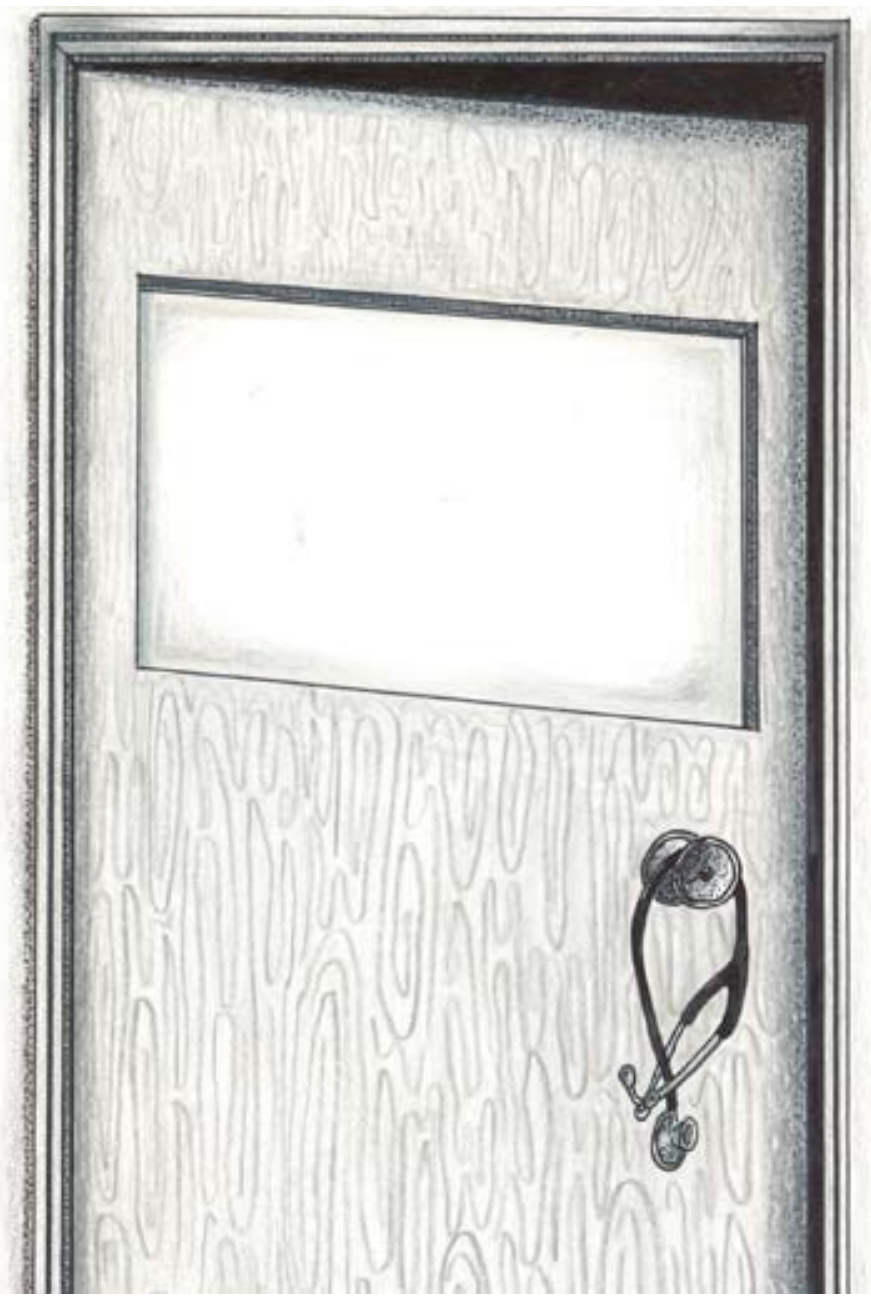

The Door - Karthika Devarajan

of the job. The emotional and interpersonal aspects of medicine can quickly become all-consuming, and the ability to separate one's private and professional life is an important one.

Mark Downing, a third-year medical student at Dalhousie, worked as a student interviewer last year as an elective credit. "[Being well-rounded] is very important, particularly in medical school," he says.

"If your work is all you have, and work becomes stressful, you have no way to relieve that stress. But if you have outlets - if you like kickboxing, if you play the guitar - you can go home and disconnect from medicine for awhile, and start afresh."

Given the high level of competition, the medical school selection process holds the same covert inscrutability as that of a secret society. While there is no "ideal" candidate per se, an online survey of current Dalhousie medical students points to certain traits and experiences 
common among successful applicants. Part 1: Analysing successful applicants, compares the pre-medical school activities and beliefs of current Dalhousie medical students. Further insight and information on the application process is offered for future applicants in Part 2: How to become a successful applicant.

\section{PART 1: Analysing the successful applicants.}

The DMJ survey was designed to examine possible factors which may lead to success in the application process, including pre-medical school activities such

\begin{tabular}{lc}
\hline \multicolumn{2}{l}{ Table 1. The percentage of survey respondents } \\
involved in pre-medical school activities \\
\hline Activity & Percentage \\
\hline Domestic volunteer work & 95 \\
Athletics & \\
(School/community/professional) & 76 \\
Extra-curricular Activities & \\
(i.e. Union, tutoring, etc) & 75 \\
International travel & 55 \\
Music (choir, band) & 53 \\
Health-related research & 51 \\
Published, peer-reviewed research & 33 \\
International volunteer work & 23 \\
\end{tabular}

as volunteer experience, travel, research and publications, as well as perceived strengths. Students were also asked to estimate their hometown population and family income during their high school years, to establish whether these factors influenced participation in such activities.

The survey generated 207 responses, representing over half the undergraduate student body. The majority of respondents were female (62\%). Distribution of respondents according to year of study was as follows: first year, 29\%, second year, $27 \%$, third year, $28 \%$ and fourth year, $16 \%$.

Students were asked to select all the activities that they were involved in prior to medical school. Domestic volunteer experience was the most common reported activity (95\%), followed by athletic involvement at a school, community or professional level (76\%). Table 1 indicates the percentage of respondents involved in selected activities.

Survey respondents were also questioned about their

\begin{tabular}{lc}
\hline \multicolumn{2}{l}{ Table 2. Estimated hometown population } \\
\hline Population Category & Percentage \\
\hline$<10000$ & 29 \\
$10000-100000$ & 29 \\
$100000-1000000$ & 37 \\
$>1000000$ & 5 \\
\hline
\end{tabular}

self-perception, specifically character traits which are relevant for someone considering a career in medicine. The most common trait in response to the question "Which of the following qualities best applied to you during your medical school application?" was "compassionate" (42). This was followed closely by "mature" (37). "Unique", "passionate" and "leadership" each generated 30 responses.

The survey questioned students about their estimated hometown population, as categorized in Table 2. The purpose was to establish whether urban and rural students were equally represented in the medical school and to examine any correlation between income status

\begin{tabular}{lc}
\hline $\begin{array}{l}\text { Table 3. Estimated annual family income at the } \\
\text { age of sixteen }\end{array}$ & Percentage \\
\hline Annual Family Income & 21 \\
\hline$\$ 0-\$ 49999$ & 43 \\
$\$ 5000-\$ 99999$ & 32 \\
$\$ 100000-\$ 249999$ & 4 \\
$>\$ 250000$ & \\
\hline
\end{tabular}

and place of residence.

Approximately $5 \%$ of respondents came from large urban centres with a population over one-million. Such distribution of students reflects Dalhousie's enrolment strategy. The majority of seats at Dalhousie Medical School are reserved for students from the Maritime Provinces, in which the largest city, Halifax, has a population under one-million.

Survey respondents were asked to estimate their family income at the age of 16 (Table 3) as well as their perception of the impact family income had in their ability to attend medical school. The majority of students selected $\$ 50,000$ - \$99,999 (43\%). A variation in high or low family incomes may be associated with the number or type of activities that define a potential student's "well-roundedness."

Students from lower-income backgrounds were 


\begin{tabular}{lcc}
\hline \multicolumn{3}{l}{ Table 4. Percentage of involved respondents based on income } \\
\hline Pre-Medical School Activities & $\begin{array}{c}\$ 50000 \\
(\%)\end{array}$ & $\begin{array}{c}>100000 \\
(\%)\end{array}$ \\
\hline Athletics & 72 & 78 \\
Domestic Volunteer Work & 93 & 95 \\
Music & 44 & 55 \\
Extra-curricular Activities & 72 & 66 \\
International Travel & 40 & 73 \\
International Volunteer Work & 16 & 28 \\
Health Related Research & 33 & 61 \\
Published Peer Reviewed Research & 28 & 30 \\
\hline
\end{tabular}

more likely to come from rural areas with a population under 10000 . In the lowest income group, 33\% of respondents came from communities of this size, as opposed to $24 \%$ of respondents with an estimated annual family income over $\$ 100000$.

This report compares the list of pre-medical school activities with the highest and lowest family income groups. The middle income group $\$ 50$ 000-\$100 000 was not included in this analysis. Illustrated in Table 4 , students in the highest and lowest income groups showed nearly equal participation in the category of domestic volunteer work; however, students from the highest-income group were more likely to have volunteered and traveled internationally.

Students from the highest-income group were also more likely to have experience in health-related research (61\%) compared to $33 \%$ of students from the lowestincome group. However, there was little difference between income groups for students whose research had been published and peer reviewed.

When asked the question "Do you believe your family income played a role in your ability to attend medical school?" one-quarter $(26 \%)$ of respondents in the under $\$ 50000$ group and two-thirds (68\%) of respondents in the over \$100 000 groups said "Yes." Significantly, lower-income students were far less likely to consider family income as a factor in their ability to attend medical school than higher-income students.

The overall majority of respondents, regardless of perceived financial status, said their family income at age 16 did not play a role in their ability to attend medical school (55\%). This suggests that, while a higher family income allowed potential applicants to participate in higher-cost activities such as international travel, students from all income groups felt confident in their potential for acceptance into medical school based on their personal strengths and experiences.

Based on the results of the survey, successful applicants to Dalhousie Medical School shared similar levels of extra-curricular involvement, with a strong emphasis on volunteer work as well as community involvement in areas such as athletics and music, prior to applying to medical school. This list of activities presented is certainly not exclusive and certain roles in such activities may have distinguished the applicants from one another.

It should be noted that, because this survey was limited to current medical students, it was not representative of the applicant pool as a whole. It can therefore be expected that more similarities than differences were found among the survey respondents regarding factors which may have led to their successful admission.

With regards to the impact of family income, this paper did not correlate hometown population with income and pre-medical school activity. It is expected that the differences in cost of living in urban and rural settings would imply that an income of less than $\$ 50$ 000 in a small town would provide more disposable income for the applicant's desired activities than a similar income in an urban setting. Again, despite these differences, over $50 \%$ of current students believed that their family's financial status did not affect their ability to attend medical school.

Although family income was a factor in the levels of participation among survey respondents for certain activities, such as international travel, the survey suggests overall that coming from a lower-income background is not necessarily a barrier to becoming "well-rounded." 


\section{PART 2: How to become a successful applicant.}

The definitive characteristic shared by current medical students as outlined by this survey was an ambitious involvement in a number of extra-curricular activities, with a strong emphasis on volunteer work. With these results, along with advice from current and former members of the admissions committee, additional insight in five key areas is provided for the next successful applicant.

\section{Get Involved}

"Success in medical school is not purely related to marks," says Dr. Renn Holness, Director of Education, Department of Surgery at Dalhousie. Holness served on the admissions committee for six years beginning in the mid-1990's.

Holness is emphatic when he talks about the importance of volunteer experience. A native Jamaican who frequently travels back to the Caribbean, he says volunteering with the poor, or in an under-serviced area, is particularly well-regarded by the admissions committee.

"If people can show a serious commitment to the underprivileged, it's very hard for the committee to say they're not interested in looking after the sick," he says.

Holness also warns against "token" volunteering, merely for the sake of the application. "It isn't about going somewhere two afternoons a week, for two weeks - we see that a lot," he says. "I'm talking about a serious commitment."

While listing volunteer work on your application demonstrates dedication and a sense of social responsibility, it is particularly relevant if your volunteer work includes interaction with patients in a medical setting.

"It's similar to applying to veterinary college," says Holness. "I've known people to apply who don't know anything at all about animals. If you have a genuine interest in human beings, and have done volunteer work, it demonstrates a certain level of commitment."

\section{Know what you are getting into}

Becoming a physician brings many rewards including respect, prestige, and a leadership role in the commu- nity. It is, however, a demanding profession which often involves late nights, erratic schedules and long hours. You must be prepared to make difficult decisions, face grieving family members and deliver bad news.

While a career in medicine is unquestionably gratifying, it is not suitable for everyone. Exposing yourself to the realities of the job - either through medically related volunteer work, discussions with your family physician, or personal research - can help you determine whether medicine is an appropriate career choice.

The common factor shared by successful applicants is their ability to articulate their reasons for pursuing a career in medicine, both in the written component of the application and in the interview. Candidates should give careful consideration to the demands of a physician's lifestyle and their personal reasons for pursuing this career.

"If you haven't been exposed to medicine at all, one would question whether you know what you're getting yourself into," says Mark Downing. "You should have an idea of what medicine will require of you."

Having a basic understanding of the Canadian health care system can also be advantageous.

"It kind of puts you off when somebody comes into the interview and you ask them simple questions about the Canada heath system, and they don't have a clue as to how medicine functions in this country," says Dr. Holness. "I think first of all candidates need to have a clear idea of what medicine in Canada involves. What are the challenges? What are the shortfalls? Knowledge of how the medical system works is definitely an asset."

\section{Communicate}

Given the intimate nature of the physician-patient relationship, the ability to communicate openly and build trust is essential.

"If you had a problem you had to take to your physician, what would you want him to ask you? What would you want to see?" Asks Dr. Stewart. "The number one characteristic is patients want their physician to care about them, and communicate that they care."

Dr. Stewart says establishing a trusting relationship with the patient is the first step toward providing proper care. 
"Competence is assumed," he says. "I've heard of physicians who don't seem to care, who have a terrible bedside manner. Well, I think that's a terrible physician, if they have a terrible bedside manner. It speaks to poor communication. If he can't communicate, he's not a good doc."

While a candidate's communication skills are tested in both oral and written form during the application process, the interview is generally the component which provokes the most anxiety among applicants. However, Dr. Stewart says interviewers make allowances for the stressful nature of the interview.

"An interview will not make a bad candidate a good candidate. And a bad interview will not make a good candidate a bad candidate. What it will do is generally support what you have said in your essay," he says.

"The demeanour of the person in the interview can give you an idea of how they react to stress, but I wouldn't rely too heavily on that, because it's such an artificial situation, and it's so early on in their career. It is up to medical education to train people to call upon their inner resources that will allow them to be calm in the middle of chaos."

Interviewers are interested in the applicant's interpersonal skills, as an indication of how they may perform in the medical school setting, as well as their ability to interact with patients in the future. At Dalhousie Medical School, where the curriculum is based on teamwork and problem-solving, strong interpersonal skills are necessities.

"You look at their ability to express their thoughts, and how passionate they are about what they're saying," says Dr. Holness. "They are confident talking to you, they are sincere, you get the feeling of honesty when they talk to you, they are well prepared for this career, and their life experiences beforehand have prepared them for this career."

"We look for a general philosophy which is focused on the human condition," says Dr. Stewart. "In general, are you interested in people contact? Some people function best in a laboratory - that's not primarily what we are looking for. We are looking for people whose research will be people-oriented."

Dr. Stewart says a candidate's personal ethics also play an important role in the application process, and he often asks a rhetorical, ethical question during the interview. One of his favourites: A couple who is being investigated for infertility goes to see their physician. The physician does a sperm count on the male, and discovers his sperm count is zero. Three weeks later, the woman comes back pregnant.

Should the physician share the fact of her husband's sterility? Should he advise marriage counselling? What should he do?

"I want the candidate to understand the ramifications of telling one without the other, of telling both," he says. "There are competing legal and ethical considerations. You have to be careful."

\section{Keep an Open Mind}

Setting personal goals for 10 years down the road doesn't mean having your plans set in stone. Keep your mind open to the possibilities of where your medical education might take you.

"You don't want to be too narrow in your focus, at this stage," says Dr. Stewart

"Ninety percent of people who come in say they want to be a general practitioner in a rural area, but they're 10 years away from that. Watch your judgement."

In the survey, students were asked which field of medicine they were currently pursuing. As stated in Table 5, family or emergency medicine was the highest-ranking response, followed by surgery (including obstetrics, gynaecology and ophthalmology).

Nearly half $(45 \%)$ the respondents said they indicated a particular area of medicine they were intending to practice on their applications.

Having a specialty in mind at the time of your application is certainly not a weakness. It shows that

Table 5. Intended medical specialties selected by current medical students

\begin{tabular}{lc}
\hline Specialty & Percentage \\
\hline Family medicine/emergency medicine & $35 \%$ \\
Surgery/OBGY/Ophthalmology & $24 \%$ \\
Internal Medicine/Neurology/Anaesthesia & $19 \%$ \\
Paediatrics & $7 \%$ \\
Pathology/Radiology & $3 \%$ \\
Research/Medical Education/Public Health & $1 \%$ \\
Psychiatry & $1 \%$ \\
Other & $1 \%$ \\
Unknown & $8 \%$ \\
\hline
\end{tabular}


you have considered which area of medicine is most appealing to you, and that you have specific goals for your career. However, it is important to be realistic about your goals, and open to the possibility that they could change after more exposure to medicine.

According to Dr. Holness, candidates who have previous experience in a specific field often want to pursue a specialty in a related field in medicine,

"I've seen people who were optometrists who want to be ophthalmologists," he says. "I've seen a few people who were in respiratory therapy, who clearly wanted to go into respirology. So for those individuals, [who have] thought out their career, and worked in the field, I think that's great. They have goals. The great majority of students, though, will not have a clear cut idea."

"I can tell you that most people in my class had no idea what they wanted to do, and some of them that did have changed their minds," says Mark Downing. "It's good to think about what you want to do, and it's a question we might ask. You should have a plan for that. But at the same time, I don't think anyone expects you to know what you want to do, when you really haven't seen much of it. You always want to be open to experience."

\section{Be Persistent}

High rejection rates at Canadian medical schools compel a vast number of applicants reapply the following year or years. While a rejection is unquestionably discouraging, it can also be viewed as an opportunity to improve one's application for the following year. Most schools offer avenues for feedback and advice on how to strengthen your application the next time around. It may be a matter of finding stronger references, improving your academic profile, or adding more volunteer work to your list of extra-curricular activities.

"Rejection doesn't mean rejection. It's the wrong word. Inability to accept is probably better terminology," says Dr. Holness.

The application process is a game of numbers; therefore rejection may be attributed as much to the limited number of spaces available as to any weaknesses in your application.

The Director of Admissions and Student Affairs at Dalhousie Medical School says applicants should take advantage of the feedback that is available upon rejection in order to increase their chances of acceptance the following year.

"We're not in the business of keeping people out of medical school - we're in the business of getting people into medical school," says Sharon Graham. "So of course we'll do everything we can to help them along the way."

\section{Conclusion}

The results of the survey, combined with the views of individuals who have played a role in the admissions process, indicate certain qualities which are desirable in a medical school applicant. Successful applicants appear to be well-rounded, with a range of interests which not only benefit their interpersonal and leadership skills, but also allow them to maintain a balanced lifestyle within a potentially stressful environment. Successful applicants also appear to possess effective communication skills which allow them to articulate how their values and life experiences have driven them to pursue a career in medicine.

The application process can be intimidating, given the exceptional qualities and achievements of the individuals within the application pool. However, it is clear that individuals from all walks of life have the potential for success in the application process, and each route taken to achieve this success is unique.

Family income may be influential in the applicant's ability to participate in higher-cost activities, such as international travel and volunteer work, which may be an asset in the application process. However, the majority of students in they survey's lowest income group indicated their financial situation did not play a role in their ability to attend medical school, which suggests the other factors outlined in the survey may play a more important role in an applicant's success or failure.

Participation in extra-curricular activities which allow an applicant to develop leadership and communication skills can be an indicator of how the applicant will perform in medical school and in a professional setting. While medical school teaches the art and science of medicine, cultivating the skills which are conducive to medicine is a process which begins long before the application process. 